\title{
Multiple Risk Factors for Heart Disease: A Challenge to the Ethnopharmacological Use of Croton urucurana Baill.
}

\author{
Priscila Megda João Job Zago (D), ${ }^{1}$ Gustavo Ratti da Silva $\left(\mathbb{D},{ }^{2}\right.$ Eduarda Carolina Amaral $\left(\mathbb{D},{ }^{1}\right.$ \\ Lorena Neris Barboza $\mathbb{D}^{1},{ }^{1}$ Fernanda de Abreu Braga $\mathbb{D}^{1},{ }^{1}$ Bethânia Rosa Lorençone $\mathbb{D}^{\mathrm{D}}{ }^{3}$ \\ Aline Aparecida Macedo Marques $\mathbb{D}^{3},{ }^{3}$ Karyne Garcia Tafarelo Moreno $\mathbb{D}^{3},^{3}$ \\ Patrícia Regina Terço Leite $\mathbb{D}^{3},{ }^{3}$ Alan de Almeida Veiga $\left(\mathbb{D},{ }^{4}\right.$ Lauro Mera de Souza $\left(\mathbb{D},{ }^{4}\right.$ \\ Roosevelt Isaias Carvalho Souza $\left(\mathrm{D},{ }^{5}\right.$ Ariany Carvalho dos Santos ${ }^{\mathrm{D}}{ }^{\mathbf{5}}$ \\ João Tadeu Ribeiro-Paes (D), 6 Arquimedes Gasparotto Junior (D), \\ and Francislaine Aparecida dos Reis Lívero $\mathbb{B}^{7}$ \\ ${ }^{1}$ Laboratory of Preclinical Research of Natural Products, \\ Post-Graduate Program in Medicinal Plants and Phytotherapeutics in Basic Attention, Paranaense University, Umuarama, \\ Paraná, Brazil \\ ${ }^{2}$ Laboratory of Preclinical Research of Natural Products, \\ Post-Graduate Program in Animal Science with Emphasis on Bioactive Products, Paranaense University, Umuarama, \\ Paraná, Brazil \\ ${ }^{3}$ Laboratory of Cardiovascular Pharmacology, Faculty of Health Sciences, Federal University of Grande Dourados, Dourados, \\ Mato Grosso do Sul, Brazil \\ ${ }^{4}$ Institute of Research Pelé Pequeno Príncipe, Pequeno Príncipe Faculty, Curitiba, Paraná, Brazil \\ ${ }^{5}$ Laboratory of Histology, Faculty of Health Sciences, Federal University of Grande Dourados, Dourados, \\ Mato Grosso do Sul, Brazil \\ ${ }^{6}$ Laboratory of Genetics and Cell Therapy, São Paulo State University, Assis, São Paulo, Brazil \\ ${ }^{7}$ Laboratory of Preclinical Research of Natural Products, \\ Post-Graduate Program in Medicinal Plants and Phytotherapeutics in Basic Attention, \\ Post-Graduate Program in Animal Science with Emphasis on Bioactive Products, Paranaense University, Umuarama, \\ Paraná, Brazil
}

Correspondence should be addressed to Francislaine Aparecida dos Reis Lívero; francislaine@prof.unipar.br

Received 4 September 2021; Revised 15 October 2021; Accepted 28 October 2021; Published 15 November 2021

Academic Editor: Daniel Kam Wah Mok

Copyright ( $\odot 2021$ Priscila Megda João Job Zago et al. This is an open access article distributed under the Creative Commons Attribution License, which permits unrestricted use, distribution, and reproduction in any medium, provided the original work is properly cited.

Croton urucurana Baill. is a native Brazilian tree, popularly known as "sangra-d'água" or "sangue-de-dragão," based on the red resinous sap of the trunk. Its use has been transmitted through generations based on popular tradition that attributes analgesic, anti-inflammatory, and cardioprotective properties to the tree. However, its cardioprotective effects have not yet been scientifically investigated. Thus, the present study investigated the pharmacological response to an ethanol-soluble fraction from the leaves of C. urucurana in Wistar rats exposed to smoking and dyslipidemia, two important cardiovascular risk factors. The extract was evaluated by high-performance liquid chromatography. Wistar rats received a $0.5 \%$ cholesterol-enriched diet and were exposed to cigarette smoke ( 9 cigarettes/day for 10 weeks). During the last 5 weeks, the animals were orally treated with vehicle (negative control group), C. urucurana extract (30, 100, and $300 \mathrm{mg} / \mathrm{kg}$ ), or simvastatin $(2.5 \mathrm{mg} / \mathrm{kg})+$ enalapril $(15 \mathrm{mg} / \mathrm{kg})$. One group of rats that was not exposed to these risk factors was also evaluated (basal group). Electrocardiograms and systolic, diastolic, and mean blood pressure were measured. Blood was collected to measure total cholesterol, triglycerides, urea, and creatinine. The heart and kidneys were collected and processed for oxidative status and histopathological evaluation. The phytochemical analysis revealed different classes of flavonoids and condensed tannins. The model induced dyslipidemia and cardiac and renal oxidative stress and increased 
levels of urea and creatinine in the negative control group. Treatment with the C. urucurana extract ( $300 \mathrm{mg} / \mathrm{kg})$ and simvastatin + enalapril decreased cholesterol and triglyceride levels. In contrast to simvastatin + enalapril treatment, the C. urucurana extract exerted cardiac and renal antioxidant effects. No alterations of electrocardiograms, blood pressure, or histopathology were observed between groups. These findings indicate that C. urucurana exerts lipid-lowering, renal, and cardioprotective effects against oxidative stress in a preclinical model of multiple risk factors for heart disease.

\section{Introduction}

Because of the high risk of morbidity and mortality associated with cardiovascular disease, finding ways to mitigate such risk has become paramount in public healthcare. The presence of classic risk factors, such as hypertension, dyslipidemia, obesity, sedentary lifestyle, smoking, diabetes, and family history, increases the risk of developing cardiovascular disease. Dyslipidemia is an important cardiovascular risk factor. Low-density lipoprotein cholesterol (LDL-c) is the most relevant modifiable risk factor for coronary artery disease [1]. Ample evidence indicates that low LDL-c levels are associated with a proportional reduction of cardiovascular outcomes, including myocardial infarction, stroke, and cardiovascular-related death [2].

Another cardiovascular risk factor is smoking, a disease that is caused by nicotine addiction. An estimated 1.25 billion smokers worldwide are at risk of early death from smoking [3]. The health consequences of smoking are disastrous, given long-term exposure of the body to harmful components in cigarettes. The long-term continued use of tobacco and its derivatives leads to the appearance of cardiovascular, oncological, and respiratory diseases, making it one of the main causes of preventable death worldwide [4].

Despite the high morbidity and mortality of cardiovascular disease, animal models that combine its main risk factors are scarce. Despite the existence of effective and lowcost pharmacological therapies, some new drugs that are recommended by recent guidelines are expensive or unavailable in public healthcare systems [5]. Thus, the search for new therapeutic agents that are less expensive and safe and act effectively for the management of cardiovascular risk factors is essential. Plants remain an important source of potential medicines and the development of new therapies.

One important native tree in Brazil is Croton urucurana Baill. (Euphorbiaceae), popularly known as "sangra-d'água" or "sangue-de-dragão." This species is widely used by the Brazilian native population as a natural source of medicines. The leaves and bark of C. urucurana are popularly used to treat various conditions, including rheumatism, wounds, gastric ulcers, liver disorders, diarrhea, cancer, and cardiovascular diseases $[6,7]$. The main active constituents of $C$. urucurana are tannins, lignans, and alkaloids [8]. Preclinical studies have shown that C. urucurana has antifungal [9], antibacterial [8], anti-inflammatory [10], antinociceptive $[6,11]$, antitumoral $[12,13]$, wound healing $[12,14]$, antiulcerogenic $[15,16]$, antidiarrheal $[17,18]$, and antihemorrhagic [19] effects. Toxicological studies reported that $C$. urucurana is potentially nontoxic, with an oral lethal dose 50 (LD50) above $5 \mathrm{~g} / \mathrm{kg}$ in mice [9].

However, despite the popular use of C. urucurana for the treatment of cardiovascular diseases [7], the cardioprotective actions of this species have not yet been pharmacologically investigated. Thus, the present study investigated the lipidlowering and antioxidant effects of an ethanol-soluble fraction obtained from leaves of C. urucurana in Wistar rats in a model of a combination of risk factors (exposure to tobacco smoke and dyslipidemia) for heart disease.

\section{Material and Methods}

2.1. Drugs. Bovine serum albumin, 5,5'-dithiobis(2-nitrobenzoic acid), reduced glutathione (GSH), xylenol orange, $\mathrm{K}_{2} \mathrm{HPO}_{4}, \mathrm{KH}_{2} \mathrm{PO}_{4}, 1 \mathrm{M}$ Tris, $5 \mathrm{mM}$ ethylenediaminetetraacetic acid, Tris $\mathrm{HCl}$ (all from Sigma, St. Louis, MO, USA), pyrogallol, absolute ethanol, absolute methanol, ferrous ammonium sulfate, trichloroacetic acid, formaldehyde (all from Vetec, Rio de Janeiro, Brazil), and ultra-pure water from a Milli-Q system were used for eluent preparation.

2.2. Extract Preparation and Phytochemical Profile. Leaves of Croton urucurana Baill. were collected in May 2020 at Dourados, Mato Grosso do Sul ("22 $20.9299^{\prime}$ south, $54^{\circ} 83.7713$ west), and a voucher specimen (no. 5536) was deposited in the Herbarium of the Federal University of Grande Dourados. The plant was dried in an oven at $50^{\circ} \mathrm{C}$ for 5 days and pulverized. The extract was prepared by infusion using the methodology of Barbosa et al. [20], in which the pulverized material (100 g) was subjected to the extraction process by infusion with $1 \mathrm{~L}$ of boiling water. The resulting infusion was kept in an amber flask for $5 \mathrm{~h}$, filtered, and then treated with $95 \%$ ethanol $(1: 3, \mathrm{v} / \mathrm{v})$ to precipitate proteins and polysaccharides, giving rise to the heterogeneous phase that was removed by filtration. The ethanol-soluble fraction was concentrated on a rotary evaporator and lyophilized. The final yield of the dried extract of C. urucurana was $11.31 \%$. Phytochemical characterization was performed using high-performance liquid chromatography (HPLC) with a diode-array detector (DAD; Shimadzu, Prominence LC-20A). Chromatography was conducted in the reverse-phase on a C18-PCP column (Ascentis Express; $150 \times 4.6 \mathrm{~mm}, 2.7 \mu \mathrm{m}$ particle size) using mobile phases that were composed of (A) $0.1 \%$ formic acid in water and (B) $0.05 \%$ formic acid in acetonitrile. The separation was obtained by a gradient of B that increased from 5\% to $30 \%$ in $15 \mathrm{~min}$ then to $80 \%$ in $20 \mathrm{~min}$, with a return to $5 \%$ in $21 \mathrm{~min}$ and then $5 \mathrm{~min}$ at the initial condition for solvent reequilibration. The flow rate was $0.5 \mathrm{ml} / \mathrm{min}$. The column temperature was held at $40^{\circ} \mathrm{C}$. Compound detection was accompanied by ultraviolet (UV) light at $190-400 \mathrm{~nm}$.

2.3. Animals. Wistar rats, weighing $150-200 \mathrm{~g}$, were obtained from the central vivarium of the Federal University of Grande Dourados. The animals were housed in the vivarium of the 
Laboratory for Pre-Clinical Research of Natural Products, Paranaense University, with free access to food and water. The animals were housed under controlled environmental conditions $\left(20^{\circ} \pm 2^{\circ} \mathrm{C}\right.$ temperature, $50 \% \pm 10 \%$ relative humidity, and $12 \mathrm{~h} / 12 \mathrm{~h}$ light/dark cycle) with environmental enrichment. The total number of animals in the experiment was 48 ( $n=8$ /group). The animals were weighed weekly on an analytical balance. The experimental protocol was approved by the Ethics Committee on the Use of Animals of Paranaense University (protocol no. 1000/2020). All national and international guidelines on animal welfare were followed. The reporting of animal investigations conformed to Animal Research Reporting of In Vivo Experiments (ARRIVE) guidelines [21].

2.4. Experimental Design. The choice of the animal species, sample size, and extract doses was based on Mendes et al. [22]. For 10 weeks, the animals received standard commercial food that was enriched with $0.5 \%$ cholesterol ad libitum. They were exposed to smoke from nine commercial cigarettes $(0.8 \mathrm{mg}$ nicotine, $10 \mathrm{mg}$ tar, and $10 \mathrm{mg}$ carbon monoxide) for $1 \mathrm{~h}$ daily, 5 days weekly, for 10 weeks, as proposed by Mendes et al. [22]. During the last 5 weeks of the experiment, the animals were treated orally by gavage with vehicle $(0.1 \mathrm{ml}$ of filtered water $/ 100 \mathrm{~g}$ body weight; negative control [C-] group), the ethanol-soluble fraction of Croton urucurana $(30,100$, and $300 \mathrm{mg} / \mathrm{kg})$, or enalapril $(15 \mathrm{mg} / \mathrm{kg})+\operatorname{sim} v a s t a t i n \quad(2.5 \mathrm{mg} / \mathrm{kg})$ once daily. Nondyslipidemic and nonsmoke-exposed Wistar rats were treated with vehicle (filtered water) and served as the basal group $(n=8)$. The final groups were the following: (1) basal (rats not exposed to any risk factor and treated with vehicle), (2) negative control ( $\mathrm{C}-$; dyslipidemic rats exposed to cigarette smoke and treated for 5 weeks with vehicle), (3) C. urucurana 30 (dyslipidemic rats exposed to cigarette smoke and treated with $30 \mathrm{mg} / \mathrm{kg}$ C. urucurana extract for 5 weeks), (4) C. urucurana 100 (dyslipidemic rats exposed to cigarette smoke and treated with $100 \mathrm{mg} / \mathrm{kg}$ C. urucurana extract for 5 weeks), (5) C. urucurana 300 (dyslipidemic rats exposed to cigarette smoke and treated with $300 \mathrm{mg} / \mathrm{kg}$ C. urucurana extract for 5 weeks), and (6) simvastatin + enalapril (dyslipidemic rats exposed to cigarette smoke and treated with $2.5 \mathrm{mg} / \mathrm{kg}$ simvastatin plus $15 \mathrm{mg} / \mathrm{kg}$ enalapril for 5 weeks).

2.5. Electrocardiography and Heart Rate and Blood Pressure Measurements. On the last day of the experiment, the rats were intramuscularly anesthetized with ketamine $(100 \mathrm{mg}$ / $\mathrm{kg})+$ xylazine $(20 \mathrm{mg} / \mathrm{kg})$. A bolus injection of heparin (15 IU) was administered subcutaneously. Electrocardiography (ECG) was recorded using a 12-lead ECG recorder (WinCardio, Micromed, Brasília, Brazil) according to Romão et al. [23]. Electrocardiographic waves were recorded for $5 \mathrm{~min}$. After ECG, the left carotid artery was isolated, cannulated, and connected to a pressure transducer that was coupled to a PowerLab recording system. Chart 4.1 software (ADI Instruments, Castle Hill, Australia) was used to record heart rate, systolic blood pressure (SBP), diastolic blood pressure (DBP), and mean arterial pressure (MAP). After
15 min of stabilization, changes in heart rate and blood pressure were recorded for $5 \mathrm{~min}$.

2.6. Blood Collection and Biochemical Analysis. Blood samples were collected from the left carotid artery using heparinized syringes. Plasma was separated by centrifugation at $1,500 \times \mathrm{g}$ for $10 \mathrm{~min}$ and stored at $-80^{\circ} \mathrm{C}$ for biochemical analyses. Total cholesterol, triglyceride, creatinine, and urea levels were measured using commercial kits and an automated analyzer (Quick Lab).

2.7. Euthanasia and Organ Collection. The rats were euthanized by puncture of the diaphragm while under anesthesia. The heart and left kidney were removed, carefully dissected, and weighed on an analytical balance. The weights of the heart and kidney were multiplied by 100 and divided by the animal's body weight before euthanasia to obtain the relative organ weight (\%). A sample of the heart and kidney was rapidly separated and frozen in liquid nitrogen to evaluate oxidative stress. Other organ samples were stored in a $10 \%$ formalin solution for further histological analysis.

2.8. Tissue Redox Status. To investigate the tissue antioxidant system, the heart and kidney samples were homogenized in a $1: 10$ dilution of potassium phosphate buffer $(0.1 \mathrm{M}, \mathrm{pH} 6.5)$. Afterward, $100 \mu \mathrm{l}$ was separated, suspended in $80 \mu \mathrm{l}$ of trichloroacetic acid (12.5\%), vortexed, and centrifuged at $6000 \times \mathrm{g}$ for $15 \mathrm{~min}$ at $4^{\circ} \mathrm{C}$. Reduced glutathione levels were measured according to Sedlak and Lindsay [24]. The remaining homogenate was centrifuged at $9000 \times \mathrm{g}$ for $20 \mathrm{~min}$ at $4^{\circ} \mathrm{C}$ for the determination of superoxide dismutase (SOD) activity and lipoperoxidation (LPO) levels according to Gao et al. [25] and Jiang et al. [26], respectively.

2.9. Histopathological Analysis. Samples of the heart and kidney were fixed in buffered $10 \%$ formalin solution (distilled water, 35-40\% formaldehyde, and monobasic and dibasic sodium phosphate), dehydrated with alcohol and xylene, embedded in paraffin, sectioned at $6 \mu \mathrm{m}$, and stained with hematoxylin/eosin. The slides were analyzed by optical microscopy (Leica DM 2500) to evaluate cellular alterations.

2.10. Statistical Analysis. The data were analyzed for homogeneity of variance and a normal distribution. Differences between means were determined by one-way analysis of variance (ANOVA) followed by the Newman-Keuls post hoc test. The level of significance was set at 95\% $(p<0.05)$. The data are expressed as the mean \pm standard error of the mean (SEM).

\section{Results}

3.1. Phytochemical Profile. The phytochemicals in the ethanol-soluble fraction from the leaf extract of Croton urucurana are described in Table 1. C. urucurana was previously investigated for the chemical composition of its leaves and stem bark. Different compounds were reported in this plant, 
TABle 1: Phytochemicals in ethanol-soluble fraction from the leaf extract of C. urucurana.

\begin{tabular}{lcccc}
\hline Peak & $R^{t}$ & UV $\lambda_{\max }$ & $\begin{array}{c}\text { Tentative } \\
\text { identification }\end{array}$ & Reference \\
\hline 1 & 2.58 & 264 & n.i. & - \\
2 & 2.81 & 200,280 & n.i. & - \\
3 & 3.31 & 261 & n.i. & - \\
4 & 3.45 & $254,278(\mathrm{Sh})$ & n.i. & - \\
5 & 8.06 & 277 & Condensed tannin & {$[27]$} \\
6 & 9.07 & 279 & Condensed tannin & {$[27]$} \\
7 & 9.66 & 278 & Condensed tannin & {$[27]$} \\
8 & 10.26 & 279 & Condensed tannin & {$[27]$} \\
9 & 11.39 & $221,268,301$ & n.i. & - \\
10 & 14.36 & 255,353 & Flavonol-O-glycoside & {$[27]$} \\
11 & 14.51 & 255,353 & Rutin & Std. $[27]$ \\
12 & 14.75 & 269,337 & Apigenin-C-glycoside & {$[27]$} \\
13 & 14.83 & 269,337 & Apigenin-C-glycoside & {$[27]$} \\
14 & 15.13 & 255,353 & Isoquercitrin & Std. $[27]$ \\
15 & 15.33 & 265,346 & Flavone C-glycoside & {$[27]$} \\
16 & 15.81 & 265,346 & Flavone C-glycoside & {$[27]$} \\
17 & 16.46 & $245,333($ Sh), & n.i. & - \\
18 & 20.35 & $229,266,316$ & n.i. & - \\
19 & 20.53 & $229,266,316$ & n.i. & - \\
20 & 20.87 & 254,366 & Quercetin & Std. \\
21 & 22.06 & 254,366 & Kaempferol & Std. \\
\hline
\end{tabular}

n.i.: not identified; Std.: compound confirmed by a comparison with authentic standard.

including flavan-3-ols, proanthocyanidins (condensed tannins), flavonols, $\mathrm{O}$-glycosides, hydroxyflavones, $\mathrm{C}$-glycosides [14, 27], alkaloids, terpenes, and phenolic acids [10], which were obtained with different extraction solvents. In the present study, comparisons with authentic standards identified some main compounds in the extract of the leaves of C. urucurana, despite the lack of information to confirm the identification of some low-abundance peaks (e.g., 1, 2, 3, and 4). Other compounds were tentatively identified based on UV spectra, supported by previous reports, but some compounds were not observed in the current extract. Alves et al. [27] performed a more comprehensive phytochemical analysis of the leaves of C. urucurana. They identified different classes of flavonoids, such as condensed tannins (e.g., proanthocyanidins). In the current extract, we identified peaks 5, 6, and 7 with UV spectra which were consistent with these compounds, with $\lambda_{\max }$ at $277-279 \mathrm{~nm}$. Condensed tannins have been reported in all investigated parts of C. urucurana $[10,14,27]$.

In addition to condensed tannins, Alves et al. [27] also described the presence of catechin. In the present study, comparisons with the catechin standard did not reveal catechin, but peak 9 was eluted close to catechin and had a similar UV spectrum, with $\lambda_{\max }$ at $279 \mathrm{~nm}$. Although unconfirmed, the isomer epicatechin has a chromatographic elution profile that is close to catechin [28] and should be considered because it was previously reported in the bark of C. urucurana [10].

Flavonol-O-glycosides were also reported in the leaves of C. urucurana [27]. These compounds have characteristic UV spectra, with an absorbance $\lambda_{\max }$ range of $350-365 \mathrm{~nm}$ from band B and 255-265 nm from band A [29]. Compound 10 had this characteristic UV spectrum and was identified as from this class of flavonoid. In contrast, the main compound that was observed on the chromatogram was identified as rutin (peak 11, $\lambda_{\max }$ at 255 and $353 \mathrm{~nm}$ ), confirmed by comparisons with the authentic standard. Isoquercitrin was also identified based on the authentic standard comparison at an Rt of $15.13 \mathrm{~min}$, with a UV spectrum that was similar to rutin.

Two other compounds (12 and 13) had $\lambda_{\max }$ at 269 and $337 \mathrm{~nm}$, which was slightly different from the characteristic UV absorption of flavonols. Alves et al. [27] described the presence of $C$-glycosides of apigenin, and these compounds have similar UV spectra as peaks 12 and 13, suggesting they belong to this flavonoid class [30]. Peaks 15 and 16 also had characteristic UV spectra that indicated flavonoid-glycosides with $\lambda_{\max }$ at 265 and $346 \mathrm{~nm}$. These compounds could not be accurately identified because in addition to rutin and isoquercitrin, Alves et al. [27] found other di- and triglycosides that were attached to myricetin, quercetin, and kaempferol. These compounds commonly appear with different glycan distributions, including several isomers, thereby hindering their identification [28, 29]. Although several glycosides were identified in the leaves of C. urucurana, no free aglycones were reported previously. Here, based on UV spectra and authentic standards, quercetin (peak 20) and kaempferol (peak 21) were also confirmed in the extract (Figure 1).

\subsection{Electrocardiographic Profile, Heart Rate, and Blood} Pressure. Electrocardiograms, heart rate, and blood pressure are shown in Table 2. No significant changes were found in the amplitude of the P-, Q-, R-, or S-waves or in the PR-, QRS-, QT-, and QTC-segments between experimental groups $(p>0.05)$. No significant alterations of heart rate or blood pressure were observed between groups $(p>0.05)$.

3.3. Body and Organ Weight. The median body weight of rats in the basal group at the end of the experiment was $166.30 \pm 3.51 \mathrm{~g}$. No differences were observed in body weight between groups $(p>0.05)$. For organ weights, we observed increases in relative weights $(\%)$ of the heart $(p<0.01)$ and kidney $(p<0.01)$ in the C-group compared with the basal group $(0.36 \% \pm 0.02 \%$ and $0.42 \% \pm 0.01 \%$, respectively). Treatment with 30,100 , and $300 \mathrm{mg} / \mathrm{kg}$ of the C. urucurana extract normalized relative heart weights $(p<0.05,0.01$, and 0.01 , respectively) and relative kidney weights $(p<0.05,0.01$, and 0.001 , respectively), whereas treatment with simvastatin + enalapril normalized only relative heart weights $(p<0.01)$. Body and organ weight are shown in Table 3.

3.4. Biochemical Profile. Dyslipidemia and smoking increased plasma triglyceride and total cholesterol levels by $117.17 \%(p<0.001)$ and $160.60 \%(p<0.001)$, respectively, compared with the basal group. Treatment with $300 \mathrm{mg} / \mathrm{kg}$ of the C. urucurana extract and simvastatin + enalapril completely reversed these changes in cholesterol $(p<0.001)$ 


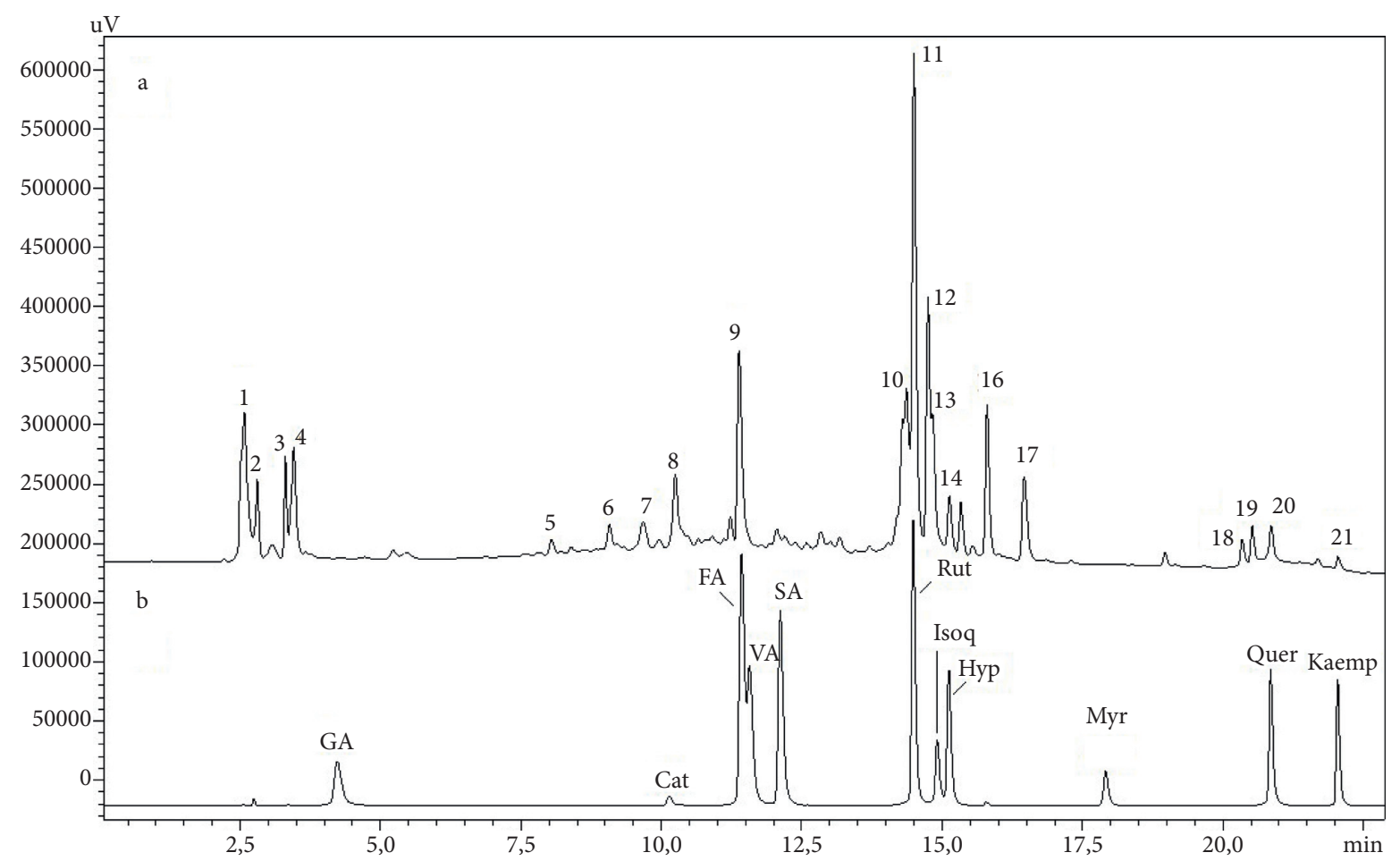

FIGURE 1: HPLC analysis of the ethanol-soluble fraction of the leaf extract of C. urucurana (A) and authentic standards (B). GA: gallic acid; cat: catechin; FA: ferulic acid; VA: vanillic acid; SA: syringic acid; rut: rutin; Isoq: isoquercitrin; Hyp: hyperoside; Myr: myricetin; Quer: quercetin; Kaemp: kaempferol.

TABLE 2: Electrocardiogram, heart rate, and blood pressure in dyslipidemic and smoking rats that were treated with vehicle, Croton urucurana extract, and simvastatin + enalapril.

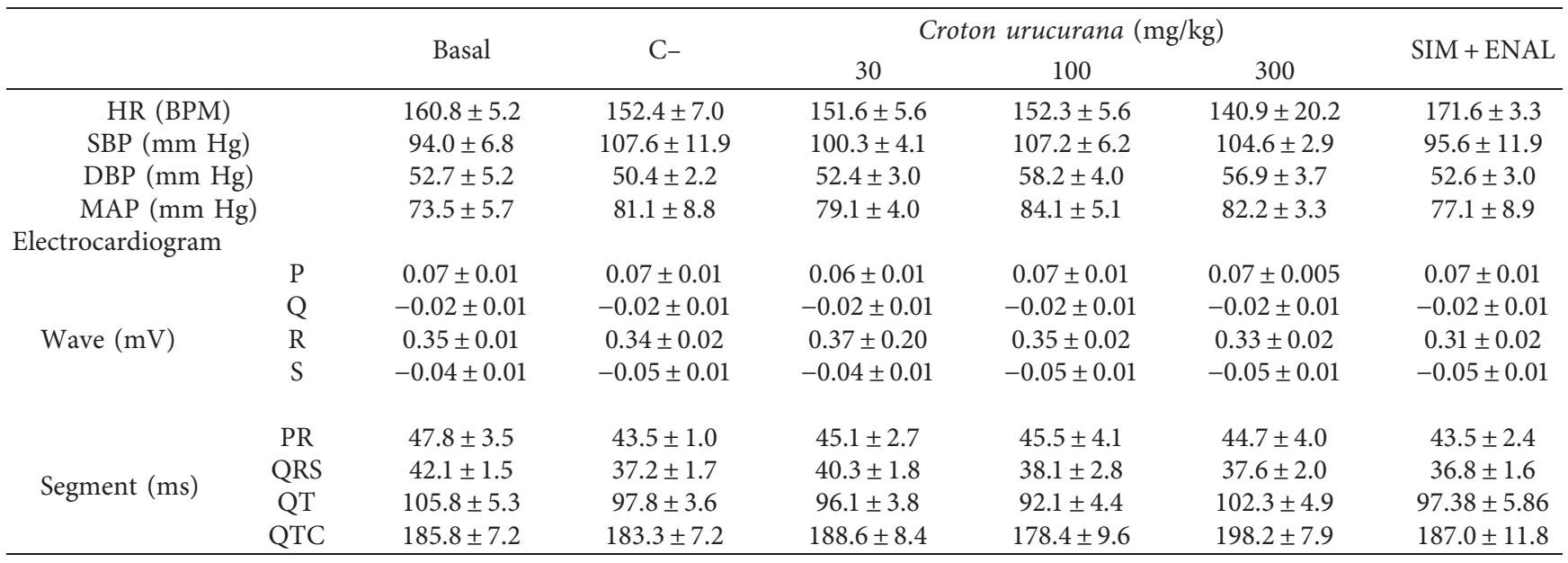

BPM: beats per minute; C-: negative control; DBP: diastolic blood pressure; HR: heart rate; MAP: mean arterial pressure; SBP: systolic blood pressure; SIM + ENAL: simvastatin + enalapril. $n=8$ /group. The data are expressed as mean \pm SEM. One-way ANOVA followed by Newman-Keuls post hoc test.

and triglycerides $(p<0.001)$, whereas treatment with 30 and $100 \mathrm{mg} / \mathrm{kg}$ of the C. urucurana extract only partially reversed triglyceride and total cholesterol levels. The risk factors also increased urea and creatinine levels compared with the basal group $(8.83 \pm 1.22 \mathrm{mg} / \mathrm{dl}, p<0.001$, and $8.50 \pm 1.25 \mathrm{mg} / \mathrm{dl}$, $p<0.001$, respectively). Treatment with $300 \mathrm{mg} / \mathrm{kg}$ of the $C$. urucurana extract completely reversed the increases in urea $(p<0.001)$ and creatinine $(p<0.001)$ levels. Treatment with 30 and $100 \mathrm{mg} / \mathrm{kg}$ of the C. urucurana extract and simvastatin + enalapril partially reversed these changes (Figure 2).

3.5. Cardiac and Renal Redox State. The combination of smoking and dyslipidemia induced significant cardiac and renal oxidative stress in Wistar rats (Figure 3). Significant decreases in cardiac and renal GSH levels were observed compared with the basal group $(150.50 \pm 4.32 \mu \mathrm{g}$ GSH/g 
TABLE 3: Body weight and relative heart and kidney weight in dyslipidemic and smoking rats that were treated with vehicle, Croton urucurana extract, and simvastatin + enalapril.

\begin{tabular}{lccccrr}
\hline & \multirow{2}{*}{ Basal } & \multirow{2}{*}{ C- } & \multicolumn{3}{c}{ Croton urucurana $(\mathrm{mg} / \mathrm{kg})$} & \multicolumn{2}{c}{ SIM + ENAL } \\
& & & 30 & 100 & 300 \\
\hline Body weight (g) & $166.3 \pm 3.5$ & $176.0 \pm 1.1$ & $174.0 \pm 3.1$ & $177.7 \pm 2.5$ & $174.9 \pm 3.2$ & $175.4 \pm 1.9$ \\
Heart (\%) & $0.36 \pm 0.02$ & $0.48 \pm 0.02^{\mathrm{a}}$ & $0.42 \pm 0.01^{\mathrm{b}}$ & $0.39 \pm 0.01^{\mathrm{b}}$ & $0.37 \pm 0.01^{\mathrm{b}}$ & $0.37 \pm 0.01^{\mathrm{b}}$ \\
Kidney (\%) & $0.42 \pm 0.01$ & $0.49 \pm 0.01^{\mathrm{a}}$ & $0.44 \pm 0.01^{\mathrm{b}}$ & $0.42 \pm 0.01^{\mathrm{b}}$ & $0.40 \pm 0.01^{\mathrm{b}}$ & $0.46 \pm 0.01$ \\
\hline
\end{tabular}

SIM + ENAL: simvastatin + enalapril. $n=8$ /group. The data are expressed as mean \pm SEM. ${ }^{a} p<0.05$ versus basal; ${ }^{b} p<0.05$ versus C- (one-way ANOVA followed by Newman-Keuls post hoc test).

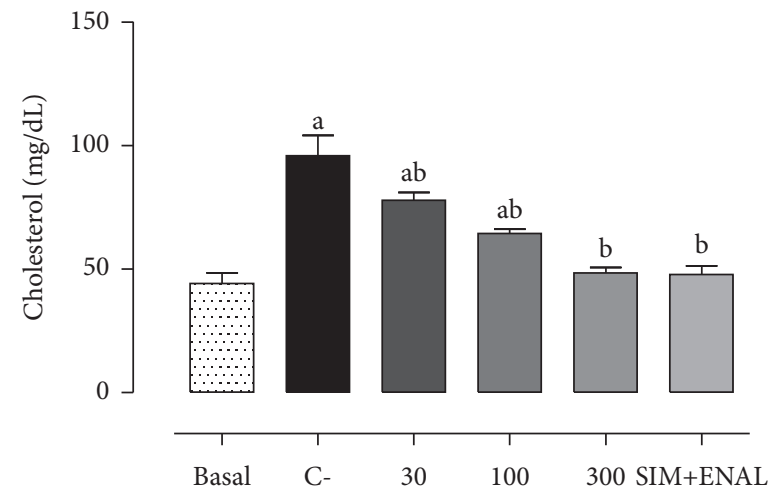

(a)

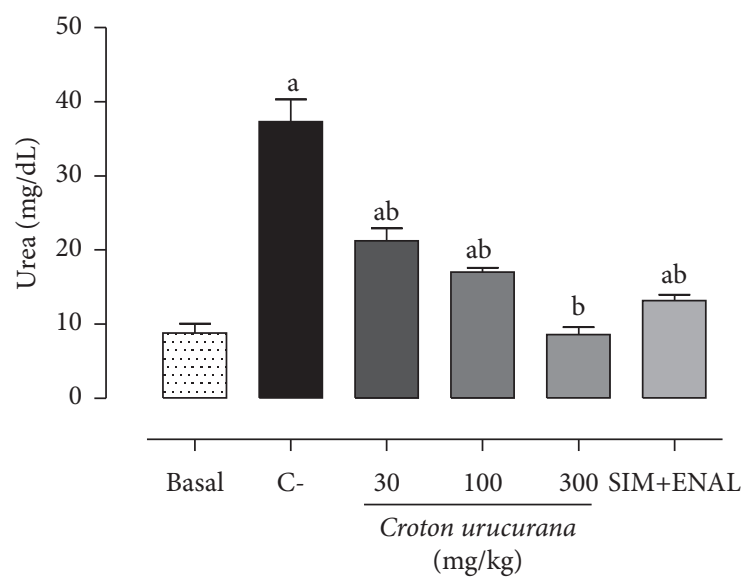

(c)

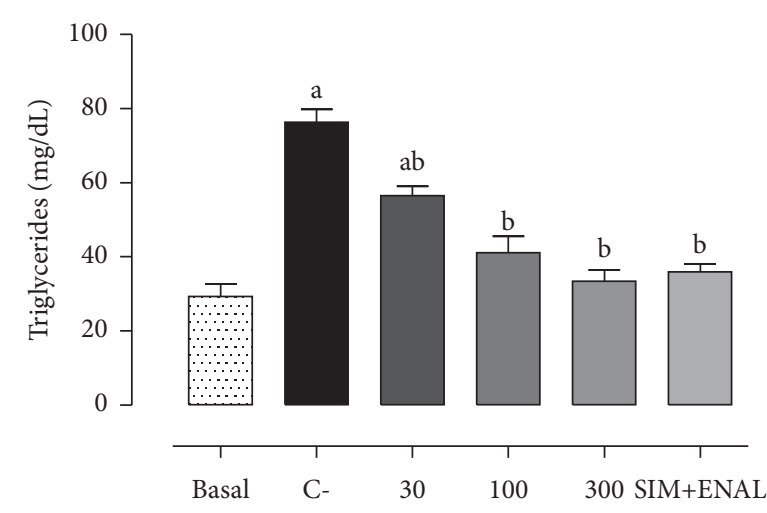

(b)

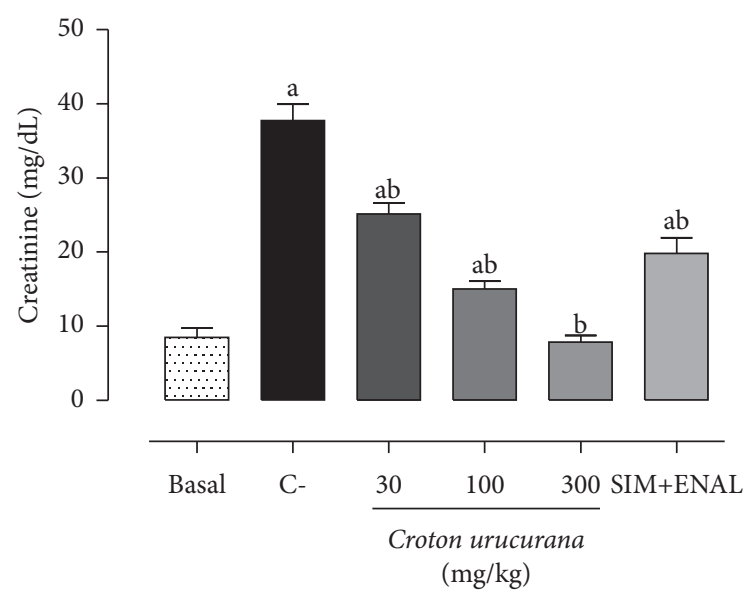

(d)

Figure 2: Effects of Croton urucurana on biochemical profile. Plasma levels of (a) cholesterol (mg/dl), (b) triglycerides (mg/dl), (c) urea $(\mathrm{mg} / \mathrm{dl})$, and $(\mathrm{d})$ creatinine $(\mathrm{mg} / \mathrm{dl})$ in nondyslipidemic and nonsmoking rats (basal group) and dyslipidemic and smoking rats that were treated with vehicle (negative control (C-)), Croton urucurana extract (30, 100, and $300 \mathrm{mg} / \mathrm{kg}$ ), or simvastatin + enalapril $(\mathrm{SIM}+\mathrm{ENAL})$. The data are expressed as mean $\pm \mathrm{SEM} .{ }^{a} p<0.05$ versus basal group; ${ }^{b} p<0.05$ versus C- group (one-way ANOVA followed by Newman-Keuls post hoc test).

tissue, $p<0.001$, and $139.30 \pm 1.58 \mu \mathrm{g} \mathrm{GSH} / \mathrm{g}$ tissue, $p<0.001$, respectively). These risk factors decreased cardiac $(p<0.001)$ and renal SOD $(p<0.001)$ activity and increased LPO levels compared with the basal group. Treatment with $300 \mathrm{mg} / \mathrm{kg}$ of the C. urucurana extract completely reversed these changes $(p<0.001)$, whereas treatment with 30 and $100 \mathrm{mg} / \mathrm{kg}$ of the C. urucurana extract and simvastatin + enalapril only partially reversed cardiac and renal oxidative stress.
3.6. Histopathological Evaluation. Heart and kidney samples stained with hematoxylin/eosin did not reveal any significant histopathological changes in any of the experimental groups (Figure 4).

\section{Discussion}

The present study investigated cardiac and renal effects of an extract of Croton urucurana using an experimental 


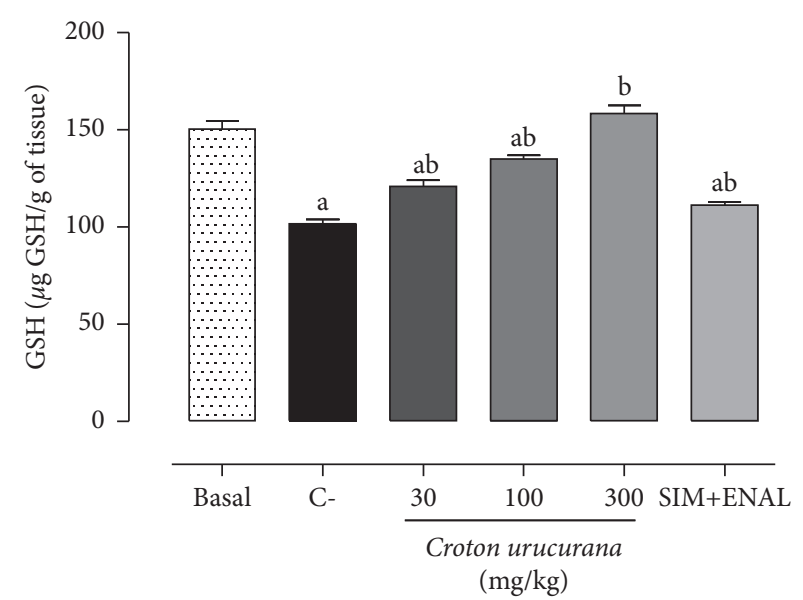

(a)

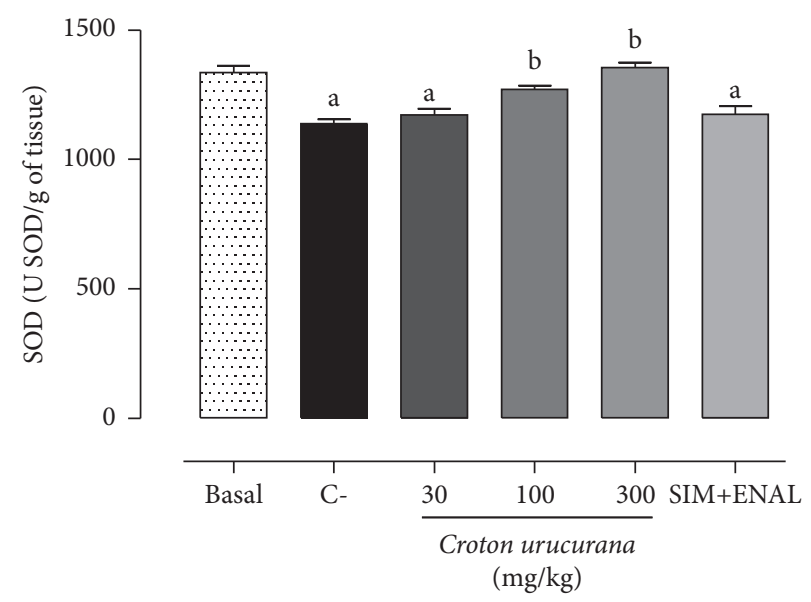

(c)

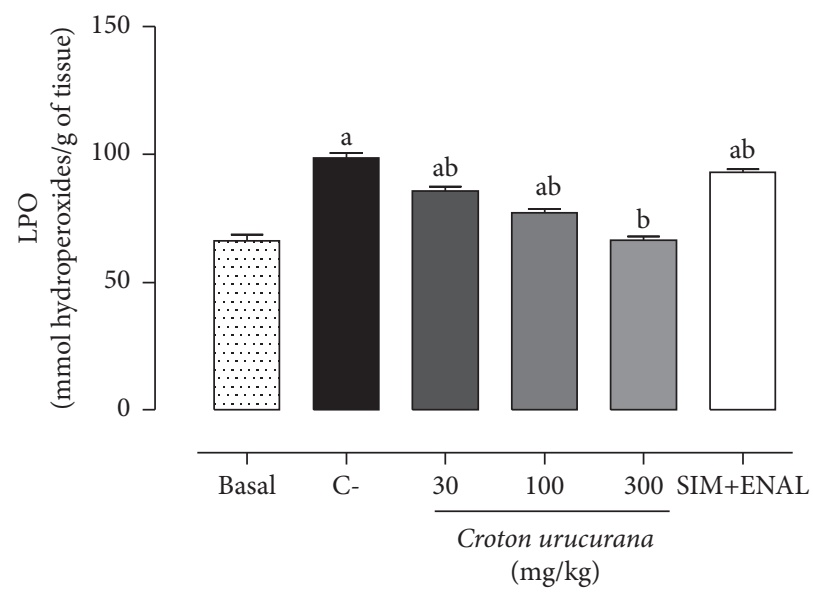

(e)

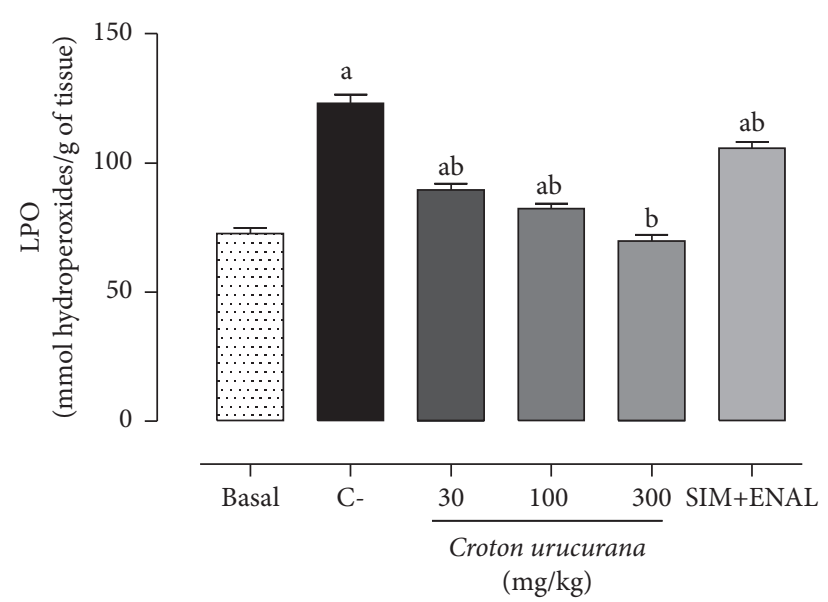

(b)

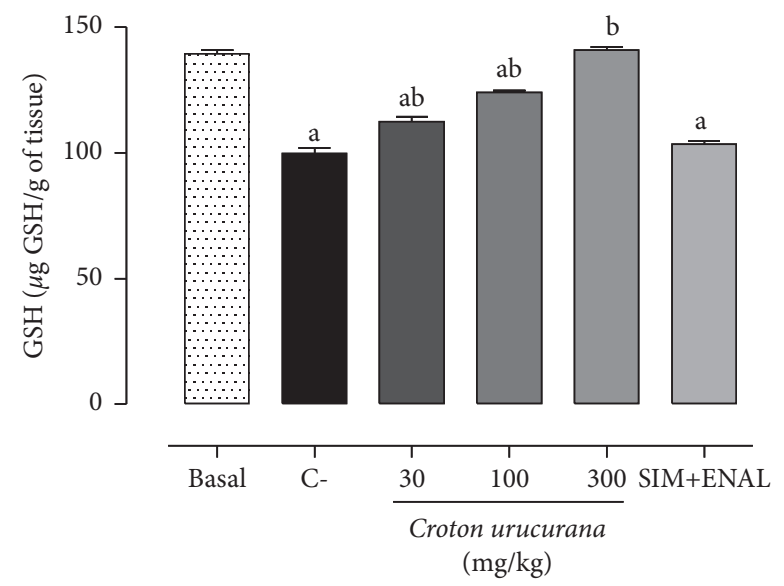

(d)

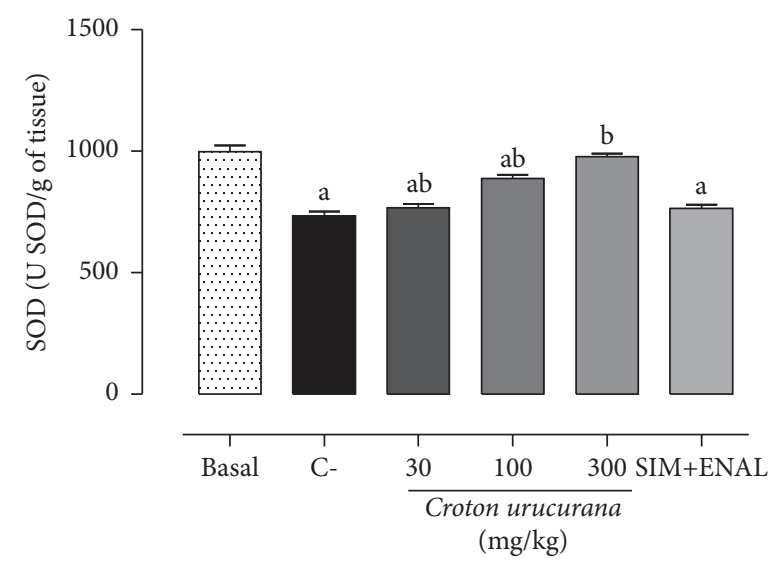

(f)

Figure 3: Antioxidant effects of Croton urucurana extract. Cardiac levels of (a) reduced glutathione, (b) lipoperoxidation, and (c) superoxide dismutase and renal levels of (d) reduced glutathione, (e) lipoperoxidation, and (f) superoxide dismutase in nondyslipidemic and nonsmoking Wistar rats (basal group) and dyslipidemic and smoking rats that were treated with vehicle (negative control (C-)), Croton urucurana extract $(30,100$, and $300 \mathrm{mg} / \mathrm{kg})$, or simvastatin + enalapril (SIM + ENAL). The data are expressed as mean \pm SEM. ${ }^{a} p<0.05$ versus basal group; ${ }^{b} p<0.05$ versus $C$ - group (one-way ANOVA followed by Newman-Keuls post hoc test). 




Figure 4: Cardiac and renal histopathological analysis. Hematoxylin/eosin staining of the heart and kidney from nondyslipidemic and nonsmoking rats (basal group) and dyslipidemic and smoking rats that were treated with vehicle (negative control (C-)), $300 \mathrm{mg} / \mathrm{kg}$ Croton urucurana extract (croton 300), and simvastatin + enalapril (SIM + ENAL). $40 \times$ magnification.

model that combined dyslipidemia and tobacco smoking, both of which are important risk factors for cardiovascular diseases. Rats exposed to a high-cholesterol diet and cigarette smoke for 10 weeks exhibited dyslipidemia, cardiac and renal oxidative stress, and high plasma levels of urea and creatinine. Daily treatment with an ethanol-soluble fraction of C. urucurana for 5 weeks effectively reversed these changes.

Because of the high morbidity and mortality of heart diseases, finding ways to prevent them has become essential in public healthcare [31]. The presence of such risk factors as hypertension, dyslipidemia, obesity, physical inactivity, smoking, diabetes, and family history significantly increases the likelihood of heart disease. When combinations of these risk factors are present, synergistic effects can occur that further aggravate the course of cardiovascular disease $[32,33]$. Despite the well-established association between multiple risk factors and heart disease, animal models that combine the main risk factors are scarce $[20,22,33]$. Thus, the use of scientifically validated preclinical models is essential to investigate and validate potential ethnobotanical candidates. 
The Western medical system has a wide range of classic drugs used to prevent and control heart disease. However, their high cost and side effects limit patients' adherence to treatment. Thus, the search is ongoing for new therapeutic agents that are effective and have a more favorable side effect profile to improve treatment adherence [34]. Given the therapeutic potential of C. urucurana for heart disease, we performed a series of preclinical studies to validate its popular usage. The results of the present study further demonstrate the potential beneficial effects of a C. urucurana extract in an animal model that utilizes a combination of two well-known cardiovascular risk factors: smoking and dyslipidemia.

The HPLC-DAD analyses identified several secondary metabolites in the C. urucurana extract, including flavonoids (i.e., rutin) and tannins (i.e., catechin). Several studies have been conducted to determine biological effects of rutin and catechin. The preventive effects of catechins on cardiovascular disease were shown to occur through the regulation of lipid metabolism, vascular endothelial protection, and blood pressure reduction [35]. In a rat model of obesity that was induced by a high-fat diet, supplementation with rutin decreased cholesterol and triglyceride levels [36, 37]. Supplementation with rutin also exerted lipid-lowering effects (i.e., a decrease in plasma triglyceride levels) in a Golden Syrian hamster model of diet-induced hypercholesterolemia [38]. Furthermore, supplementation with rutin $(100 \mathrm{mg} / \mathrm{kg})$ improved kidney and heart morphology and function in a rat model of chronic kidney disease, promoting reno- and cardioprotective effects [39]. Antioxidant effects of rutin were also previously reported in preclinical studies [36, 40, 41]. Evidence from preclinical and clinical studies also revealed antioxidant effects of catechin [42-46]. Despite strong evidence of the participation of rutin and catechin in the lipid-lowering, antioxidant, and renoprotective effects of C. urucurana, we do exclude the possibility that other compounds may also be involved in its beneficial effects. We speculate that the pharmacological effects that were observed in the present study may be attributable to an integrated action of several secondary metabolites that act both independently and in a coordinated manner on different molecular targets.

The antioxidant and renoprotective effects of C. urucurana were superior to the simvastatin + enalapriltreated group. Although some studies showed that simvastatin exerted antioxidant effects [47, 48], we did not observe such a significant effect in the present model. Furthermore, previous studies indicated that enalapril worsened renal function in patients with heart disease by inhibiting the angiotensin-converting enzyme. Thus, enalapril appears to cause direct intrarenal vasoconstriction, reducing perfusion pressure of the renal afferent arteriole, decreasing glomerular filtration, and worsening kidney function [49-51]. Treatment with the C. urucurana extract did not alter renal function and instead had antioxidant actions, thus highlighting the advantage of this treatment relative to simvastatin and enalapril.

In summary, we found that treatment with the C. urucurana extract, mainly at the highest dose, exerted reno- and cardioprotective effects against smoking- and dyslipidemia-induced damage in Wistar rats. These results will likely contribute to further studies to validate these preclinical effects in human patients. Despite these encouraging data, the important limitations of this study are worth mentioning. First, we did not determine the molecular mechanisms by which the C. urucurana extract exerted its pharmacological effects. Furthermore, we did not evaluate the possible synergistic or additive effects of C. urucurana combined with simvastatin or enalapril. Future studies should investigate whether the cardioprotective effects of C. urucurana could be improved by the concomitant administration of a classic cardioprotective drug.

\section{Conclusion}

The Croton urucurana extract exerted reno- and cardioprotective effects in a rat model of smoking- and dyslipidemia-induced heart disease.

\section{Abbreviations}

ANOVA: Analysis of variance

DAD: Diode-array detector

DBP: Diastolic blood pressure

ECG: Electrocardiography

GSH: $\quad$ Reduced glutathione

HPLC: High-performance liquid chromatography

LD50: Lethal dose 50

LDL-c: Low-density lipoprotein cholesterol

LPO: Lipoperoxidation

MAP: Mean arterial pressure

SBP: $\quad$ Systolic blood pressure

SEM: $\quad$ Standard error of the mean

SOD: $\quad$ Superoxide dismutase

UV: Ultraviolet.

\section{Data Availability}

Data will be available upon request to the corresponding author (e-mail: francislaine@prof.unipar.br).

\section{Conflicts of Interest}

The authors declare that they have no conflicts of interest related to this research.

\section{Authors' Contributions}

PMJJZ, GRS, ECA, LNB, FAB, BRL, AAMM, KGTM, PRTL, and FARL were responsible for the animal experiments and extract preparation. RICS and ACS contributed to the histological analyses. AAV and LMS performed the phytochemical analyses. PMJJZ, AGJ, and FARL were responsible for data discussion and manuscript elaboration. JTRP, AGJ, and FARL contributed to data interpretation and manuscript preparation. FARL was the senior researcher who was responsible for the project. 


\section{Acknowledgments}

The authors thank students in the Laboratory of Preclinical Research of Natural Products (Paranaense University) and Laboratory of Cardiovascular Pharmacology (Federal University of Grande Dourados) for help with the experiments and Michael Arends for proofreading the manuscript. This research was supported by grants from Coordenadoria de Pós-Graduação (COPG, Paranaense University, Brazil), Conselho Nacional de Desenvolvimento Científico e Tecnológico $(\mathrm{CNPq})$, and Fundação Araucária, Paraná/SETI (Brazil, CP 20/2018, 014/2020).

\section{References}

[1] D. J. Aggarwal, M. G. Kathariya, and D. P. K. Verma, "LDL-C, NON-HDL-C and APO-B for cardiovascular risk assessment: looking for the ideal marker," Indian Heart Journal, vol. 73, no. 5, pp. 544-548, 2021.

[2] K. C. Koskinas, G. C. M. Siontis, R. Piccolo et al., "Effect of statins and non-statin LDL-lowering medications on cardiovascular outcomes in secondary prevention: a metaanalysis of randomized trials," European Heart Journal, vol. 39, no. 14, pp. 1172-1180, 2018.

[3] T. Münzel, O. Hahad, M. Kuntic, J. F. Keaney, J. E. Deanfield, and A. Daiber, "Effects of tobacco cigarettes, e-cigarettes, and waterpipe smoking on endothelial function and clinical outcomes," European Heart Journal, vol. 41, no. 41, pp. 4057-4070, 2020.

[4] W. K. Balwan and S. Kour, "Lifestyle diseases: the link between modern lifestyle and threat to public health," Saudi Journal of Medical and Pharmaceutical Sciences, vol. 7, no. 4, pp. 179-184, 2021.

[5] Y. Zhu, J. P. Moriarty, K. M. Swanson et al., "A model-based cost-effectiveness analysis of pharmacogenomic panel testing in cardiovascular disease management: preemptive, reactive, or none?" Genetics in Medicine, vol. 23, no. 3, pp. 461-470, 2021.

[6] V. S. Rao, L. A. Gurgel, R. C. P. Lima-Júnior, D. T. O. Martins, V. Cechinel-Filho, and F. A. Santos, "Dragon's blood from Croton urucurana (Baill.) attenuates visceral nociception in mice," Journal of Ethnopharmacology, vol. 113, no. 2, pp. 357-360, 2007.

[7] F. C. Coelho, C. A. S. Tirloni, A. A. M. Marques, F. M. Gasparotto, F. A. D. R. Lívero, and A. Gasparotto Junior, "Traditional plants used by remaining healers from the region of Grande Dourados, Mato Grosso do Sul, Brazil," Journal of Religion and Health, vol. 58, no. 2, pp. 572-588, 2019.

[8] M. T. L. P. Peres, F. D. Monache, A. B. Cruz, M. G. Pizzolatti, and R. A. Yunes, "Chemical composition and antimicrobial activity of Croton urucurana Baillon (Euphorbiaceae)," Journal of Ethnopharmacology, vol. 56, no. 3, pp. 223-226, 1997.

[9] L. A. Gurgel, J. J. C. Sidrim, D. T. Martins, V. C. Filho, and V. S. Rao, "In vitro antifungal activity of dragon's blood from Croton urucurana against dermatophytes," Journal of Ethnopharmacology, vol. 97, no. 2, pp. 409-412, 2005.

[10] K. W. Cordeiro, J. L. Felipe, K. F. Malange et al., “Anti-inflammatory and antinociceptive activities of Croton urucurana Baillon bark," Journal of Ethnopharmacology, vol. 183, pp. 128-135, 2016.

[11] M. T. L. P. Peres, F. D. Monache, M. G. Pizzolatti et al., "Analgesic compounds of Croton urucurana Baillon.
Pharmaco-chemical criteria used in their isolation," Phytotherapy Research, vol. 12, no. 3, pp. 209-211, 1998.

[12] Z.-P. Chen, Y. Cai, and J. Phillipson, "Studies on the antitumour, anti-bacterial, and wound-healing properties of dragon's Blood1," Planta Medica, vol. 60, no. 6, pp. 541-545, 1994.

[13] P. de Matos Cândido-Bacani, F. Ezan, P. de Oliveira Figueiredo et al., "[1-9-N $\alpha \mathrm{C}]$-crourorb A1 isolated from Croton urucurana latex induces G2/M cell cycle arrest and apoptosis in human hepatocarcinoma cells," Toxicology Letters, vol. 273, pp. 44-54, 2017.

[14] T. D. R. L. Casao, C. G. Pinheiro, M. M. Sarandy et al., "Croton urucurana Baillon stem bark ointment accelerates the closure of cutaneous wounds in knockout IL-10 mice," Journal of Ethnopharmacology, vol. 261, Article ID 113042, 2020.

[15] M. J. S. Miller, W. K. MacNaughton, X.-J. Zhang et al., "Treatment of gastric ulcers and diarrhea with the Amazonian herbal medicine sangre de grado," American Journal of Physiology-Gastrointestinal and Liver Physiology, vol. 279, no. 1, pp. G192-G200, 2000.

[16] K. Wolff Cordeiro, L. Aparecida Pinto, A. S. Nazari Formagio, S. Faloni de Andrade, C. A. Leite Kassuya, and K. de Cássia Freitas, "Antiulcerogenic effect of Croton urucurana Baillon bark," Journal of Ethnopharmacology, vol. 143, no. 1, pp. 331-337, 2012.

[17] L. A. Gurgel, R. M. Silva, F. A. Santos, D. T. O. Martins, P. O. Mattos, and V. S. N. Rao, "Studies on the antidiarrhoeal effect of dragon's blood from Croton urucurana," Phytotherapy Research, vol. 15, no. 4, pp. 319-322, 2001.

[18] D. S. V. Barbieri, F. Tonial, P. V. A. Lopez et al., "Antiadherent activity of Schinus terebinthifolius and Croton urucurana extracts on in vitro biofilm formation of Candida albicans and Streptococcus mutans," Archives of Oral Biology, vol. 59, no. 9, pp. 887-896, 2014.

[19] L. E. Esmeraldino, A. M. Souza, and S. V. Sampaio, "Evaluation of the effect of aqueous extract of Croton urucurana Baillon (Euphorbiaceae) on the hemorrhagic activity induced by the venom of Bothrops jararaca, using new techniques to quantify hemorrhagic activity in rat skin," Phytomedicine, vol. 12, no. 8, pp. 570-576, 2005.

[20] R. J. Barbosa, G. R. Silva, I. M. Cola et al., "Promising therapeutic use of Baccharis trimera (Less.) DC. as a natural hepatoprotective agent against hepatic lesions that are caused by multiple risk factors," Journal of Ethnopharmacology, vol. 254, Article ID 112729, 2020.

[21] N. Percie du Sert, V. Hurst, A. Ahluwalia et al., "The ARRIVE guidelines 2.0: updated guidelines for reporting animal research," PLoS Biology, vol. 18, no. 7, Article ID e3000410, 2020.

[22] T. C. Mendes, G. R. Silva, A. O. Silva et al., "Hepato- and cardioprotective effects of Baccharis trimera (Less.) DC. against multiple risk factors for chronic noncommunicable diseases," Anais da Academia Brasileira de Ciências, vol. 93, Article ID e20200899, 2021.

[23] P. V. M. Romão, R. A. C. Palozi, L. P. Guarnier et al., "Cardioprotective effects of Plinia cauliflora (Mart.) Kausel in a rabbit model of doxorubicin-induced heart failure," Journal of Ethnopharmacology, vol. 242, Article ID 112042, 2019.

[24] J. Sedlak and R. H. Lindsay, "Estimation of total, proteinbound, and nonprotein sulfhydryl groups in tissue with Ellman's reagent," Analytical Biochemistry, vol. 25, pp. 192-205, 1968.

[25] R. Gao, Z. Yuan, Z. Zhao, and X. Gao, "Mechanism of pyrogallol autoxidation and determination of superoxide 
dismutase enzyme activity," Bioelectrochemistry and Bioenergetics, vol. 45, no. 1, pp. 41-45, 1998.

[26] J. Jiang, D. Kosman, Y. T. Ip, and M. Levine, "The dorsal morphogen gradient regulates the mesoderm determinant twist in early Drosophila embryos," Genes \& Development, vol. 5, no. 10, pp. 1881-1891, 1991.

[27] J. J. L. Alves, M. I. Dias, J. C. M. Barreira et al., "Phenolic profile of Croton urucurana Baill. leaves, stems and bark: pairwise influence of drying temperature and extraction solvent," Molecules, vol. 25, no. 9, p. 2032, 2020.

[28] L. M. Souza, T. R. Cipriani, M. Iacomini, P. A. J. Gorin, and G. L. Sassaki, "HPLC/ESI-MS and NMR analysis of flavonoids and tannins in bioactive extract from leaves of Maytenus ilicifolia," Journal of Pharmaceutical and Biomedical Analysis, vol. 47, no. 1, pp. 59-67, 2008.

[29] L. M. Souza, T. R. Cipriani, C. F. Sant'Ana, M. Iacomini, P. A. J. Gorin, and G. L. Sassaki, "Heart-cutting two-dimensional (size exclusion $\times$ reversed phase) liquid chromatography-mass spectrometry analysis of flavonol glycosides from leaves of Maytenus ilicifolia," Journal of Chromatography $A$, vol. 1216, no. 1, pp. 99-105, 2009.

[30] T. B. L. Prando, L. N. Barboza, V. O. Araújo et al., "Involvement of bradykinin B2 and muscarinic receptors in the prolonged diuretic and antihypertensive properties of Echinodorus grandiflorus (Cham. \& Schltdl.)," Phytomedicine, vol. 23, no. 11, pp. 1249-1258, 2016.

[31] D. P Leong, P. G. Joseph, M. McKee et al., "Reducing the global burden of cardiovascular disease, part 2: prevention and treatment of cardiovascular disease," Circulation Research, vol. 121, no. 6, pp. 695-710, 2017.

[32] S. Francula-Zaninovic and I. A. Nola, "Management of measurable variable cardiovascular disease' risk factors," Current Cardiology Reviews, vol. 14, no. 3, pp. 153-163, 2018.

[33] M. M. Q. Souza, G. R. Silva, I. M. Cola et al., "Baccharis trimera (Less.) DC: an innovative cardioprotective herbal medicine against multiple risk factors for cardiovascular disease," Journal of Medicinal Food, vol. 23, no. 6, pp. 676-684, 2020.

[34] M. Aggarwal, B. Aggarwal, and J. Rao, "Integrative medicine for cardiovascular disease and prevention," Medical Clinics of North America, vol. 101, no. 5, pp. 895-923, 2017.

[35] X. Q. Chen, T. Hu, Y. Han et al., "Preventive effects of catechins on cardiovascular disease," Molecules, vol. 21, no. 12, p. 1759, 2016.

[36] C. L. Hsu, C. H. Wu, S. L. Huang, and G. C. Yen, "Phenolic compounds rutin and o-coumaric acid ameliorate obesity induced by high-fat diet in rats," Journal of Agricultural and Food Chemistry, vol. 57, no. 2, pp. 425-431, 2009.

[37] A. Ziaee, F. Zamansoltani, M. Nassiri-Asl, and E. Abbasi, "Effects of rutin on lipid profile in hypercholesterolaemic rats," Basic and Clinical Pharmacology and Toxicology, vol. 104, no. 3, pp. 253-258, 2009.

[38] A. Kanashiro, D. C. Andrade, L. M. Kabeya et al., "Modulatory effects of rutin on biochemical and hematological parameters in hypercholesterolemic Golden Syrian hamsters," Anais da Academia Brasileira de Ciências, vol. 81, pp. 67-72, 2009.

[39] V. Diwan, L. Brown, and G. C. Gobe, "The flavonoid rutin improves kidney and heart structure and function in an adenine-induced rat model of chronic kidney disease," Journal of Functional Foods, vol. 33, pp. 85-93, 2017.

[40] M. Karthick, P. Stanely, and M. Prince, "Preventive effect of rutin, a bioflavonoid, on lipid peroxides and antioxidants in isoproterenol-induced myocardial infarction in rats," Journal of Pharmacy and Pharmacology, vol. 58, no. 5, pp. 701-707, 2006.

[41] İ. Topal, A. Ö. Bilgin, F. K. Çimen et al., "The effect of rutin on cisplatin-induced oxidative cardiac damage in rats," The Anatolian Journal of Cardiology, vol. 20, no. 3, pp. 136-142, 2018.

[42] D. L. McKay and J. B. Blumberg, "Roles for epigallocatechin gallate in cardiovascular disease and obesity: an introduction," Journal of the American College of Nutrition, vol. 26, no. 4, pp. 362S-365S, 2013.

[43] A. Chowdhury, J. Sarkar, T. Chakraborti, P. K. Pramanik, and S. Chakraborti, "Protective role of epigallocatechin-3-gallate in health and disease: a perspective," Biomedicine \& Pharmacotherapy, vol. 78, pp. 50-59, 2016.

[44] M. Grzesik, K. Naparło, G. Bartosz, and I. Sadowska-Bartosz, "Antioxidant properties of catechins: comparison with other antioxidants," Food Chemistry, vol. 241, pp. 480-492, 2018.

[45] M. P. Mudagal and K. Swathi, "Role of quercetin and catechin in attenuation of isoproterenol induced bioflavonoids, myocardial infarction in rats," Asian Journal of Pharmacy and Pharmacology, vol. 4, no. 5, pp. 662-667, 2018.

[46] K. Venkatakrishnan, H. F. Chiu, J. C. Cheng et al., "Comparative studies on the hypolipidemic, antioxidant and hepatoprotective activities of catechin-enriched green and oolong tea in a double-blind clinical trial," Food \& Function, vol. 9, no. 1, pp. 1205-1213, 2018.

[47] T. Nikolic, V. Zivkovic, I. Srejovic et al., "Effects of atorvastatin and simvastatin on oxidative stress in diet-induced hyperhomocysteinemia in Wistar albino rats: a comparative study," Molecular and Cellular Biochemistry, vol. 437, no. 1, pp. 109-118, 2018.

[48] H. A. Abd El Aal, L. A. Ahmed, W. A. Hassan, H. M. Fawzy, and H. Moawad, "Combination of carvacrol with simvastatin improves the lipid-lowering efficacy and alleviates simvastatin side effects," Journal of Biochemical and Molecular Toxicology, vol. 31, no. 12, Article ID e21981, 2017.

[49] H. C. Rayner, M. E. Thomas, and D. V. Milford, "What have you been taking? Nephrotoxicity from medications and other chemicals," in Understanding Kidney DiseasesSpringer, Berlin, Germany, 2020.

[50] Z. Kanic, V. Kanic, and T. Hojnik, "Enalapril and Acute Kidney Injury in a hypertensive premature newborn-should it be used or not?" Journal of Pediatric Pharmacology and Therapeutics, vol. 26, no. 6, pp. 638-642, 2021.

[51] W. McCallum, H. Tighiouart, E. Ku, D. Salem, and M. J. Sarnak, "Trends in kidney function outcomes following RAAS inhibition in patients with heart failure with reduced ejection fraction," American Journal of Kidney Diseases, vol. 75, no. 1, pp. 21-29, 2020. 